\title{
O surgimento de novas regiões metropolitanas no Brasil: uma discussão a respeito do caso de Sorocaba (SP)
}

The constitution of metropolitans regions in Brazil : a discussion about Sorocaba (SP)

L'émergence de nouvelles régions métropolitaines : une discussion autour du cas de Sorocaba (SP)

Ilson Juliano Barreto

\section{(2) OpenEdition}

\section{Journals}

\section{Edição electrónica}

URL: https://journals.openedition.org/espacoeconomia/374

DOI: $10.4000 /$ espacoeconomia.374

ISSN: 2317-7837

\section{Editora}

Núcleo de Pesquisa Espaço \& Economia

\section{Refêrencia eletrónica}

Ilson Juliano Barreto, «O surgimento de novas regiões metropolitanas no Brasil: uma discussão a respeito do caso de Sorocaba (SP)», Espaço e Economia [Online], 1 | 2012, posto online no dia 15 abril 2013, consultado o 21 setembro 2021. URL: http://journals.openedition.org/espacoeconomia/374 ; DOI: https://doi.org/10.4000/espacoeconomia.374

Este documento foi criado de forma automática no dia 21 setembro 2021.

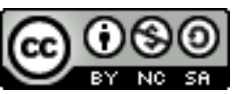

Espaço e Economia - Revista brasileira de geografia econômica est mise à disposition selon les termes de la licence Creative Commons Attribution - Pas d'Utilisation Commerciale - Partage dans les Mêmes Conditions 4.0 International. 


\section{O surgimento de novas regiões metropolitanas no Brasil: uma discussão a respeito do caso de Sorocaba (SP)}

The constitution of metropolitans regions in Brazil : a discussion about Sorocaba $(\mathrm{SP})$ L'émergence de nouvelles régions métropolitaines : une discussion autour du cas de Sorocaba (SP)

Ilson Juliano Barreto

\section{Introdução}

1 Aos que se lançam no estudo das regiões metropolitanas brasileiras, o ano de 1973 tem especial significância, haja vista que, no referido ano, são criadas as primeiras regiões metropolitanas brasileiras, por força da Lei Complementar $n^{\circ} 14$ /1973. Assim, foram institucionalizadas inicialmente, nove regiões metropolitanas: as de São Paulo, Belo Horizonte, Porto Alegre, Curitiba, Salvador, Recife, Fortaleza, Belém e Rio de Janeiro, esta última em 1974. Neste período, sabidamente sob o crivo do governo militar, a intenção primordial era a de se estabelecer uma integração do território brasileiro forjada numa desejada e intensa inter-relação entre essas unidades político-administrativas e alicerçada numa sociedade que, ali, nos primeiros anos daquela década, já se mostrava com forte tendência à concentração nesses grandes centros urbanos. Portanto, essa política de integração do territorial do país, desejada a partir da criação dessas primeiras regiões metropolitanas partia da premissa de que tal empreitada estava ligada diretamente ao fato de se começar a construir -- a partir das ações descritas neste parágrafo -- uma sociedade fortemente concentrada no meio urbano. 
2 Este modelo inicial de condução do fato metropolitano foi marcado por um modelo de administração altamente centralizado e, portanto, com pouco poder decisório às bases locais, essencialmente as municipais, estas últimas, organismos vitais e indispensáveis a um governo metropolitano plural e participativo das unidades que o compõe.

3 Até o início dos anos de 1990, ainda se mantinham as nove regiões metropolitanas iniciais, mas, a partir daí - por força da Constituição de 1988, que delegou aos governos das unidades da federação a incumbência da criação de novas regiões metropolitanas -- o que se percebe então, é uma verdadeira "boom" quantitativo das mesmas, em especial, depois de 1994. Atualmente, segundo o IBGE, são 36 Regiões Metropolitanas oficiais, muitas delas, motivo de intensa discussão entre os que se debruçam sobre o estudo das mesmas, principalmente no que se refere aos critérios utilizados no processo de criação dessas unidades político-administrativas, com destaque ao fato de muitas das novas regiões metropolitanas não possuírem ainda, sequer, um contingente populacional significativo que justifique a sua institucionalização.

4 A nossa intenção com este artigo é a de promover uma discussão a respeito da criação de novas regiões metropolitanas no Brasil trazendo à baila as ações dos agentes envolvidos em tal processo e a legitimidade na criação das mesmas. Para isso, faremos uso dos resultados obtidos em nossos estudos atuais que têm como alvo o processo de criação da Região Metropolitana de Sorocaba.

\section{Por uma crítica à ausência de critérios na criação de novas regiões metropolitanas no país: as disparidades quantitativa e qualitativa no cenário metropolitano brasileiro}

5 Os números do IBGE, oriundos do Censo 2010 (tabela 1), nos mostra claramente a grande disparidade populacional existente entre as regiões metropolitanas brasileiras atuais.

6 Por um lado, temos a maior região metropolitana do país, sabidamente a de São Paulo, com 39 municípios integrantes e população próxima a 20 milhões de habitantes; por outro, em último lugar no ranking populacional, está a Região Metropolitana do Sudoeste Maranhense, com 8 municípios integrantes e população pouco superior a $300 \mathrm{mil}$ habitantes. Embora outros critérios sejam igualmente importantes ao do contingente populacional, indubitavelmente, este último tem significativa relevância na justificativa da criação de uma região metropolitana. É preciso então considerar até que ponto as regiões metropolitanas recentes, as de iniciativa estadual, podem ser efetivamente identificadas nessa categoria (cf. DAVIDOVICH, 2003, p.62).

7 Destacamos parágrafo anterior, a discrepância entre as populações das regiões metropolitanas brasileiras, porém, outros elementos merecem destaque. Ainda com base nos dados constantes na tabela 1, um fato importante é o que diz respeito à relação entre o período de criação das referidas regiões metropolitanas e seus contingentes populacionais.

8 As primeiras (criadas no início da década de 1970), com exceção da Região Metropolitana de Belém, possuem atualmente população superior a dois milhões de habitantes; excetuando-se a capital paraense, todas as outras regiões metropolitanas antigas encabeçam os primeiros lugares no ranking das mais populosas. Isso nos mostra que, 
embora haja uma variação de crescimento de uma região metropolitana para outra, e até mesmo entre as os municípios que as compõem, as primeiras regiões metropolitanas criadas no país continuam sendo importantes núcleos de atração populacional. o segundo elemento que merece destaque diz respeito ao fato de as regiões metropolitanas mais antigas, invariavelmente possuírem como cidade pólo, capitais de estados. Em contrapartida, as regiões metropolitanas recentes, de iniciativa estadual, portanto, criadas depois de 1988, possuem como cidade pólo, em sua grande maioria, aquelas que não são capitais estaduais.

Regiões Metropolitanas Brasileiras

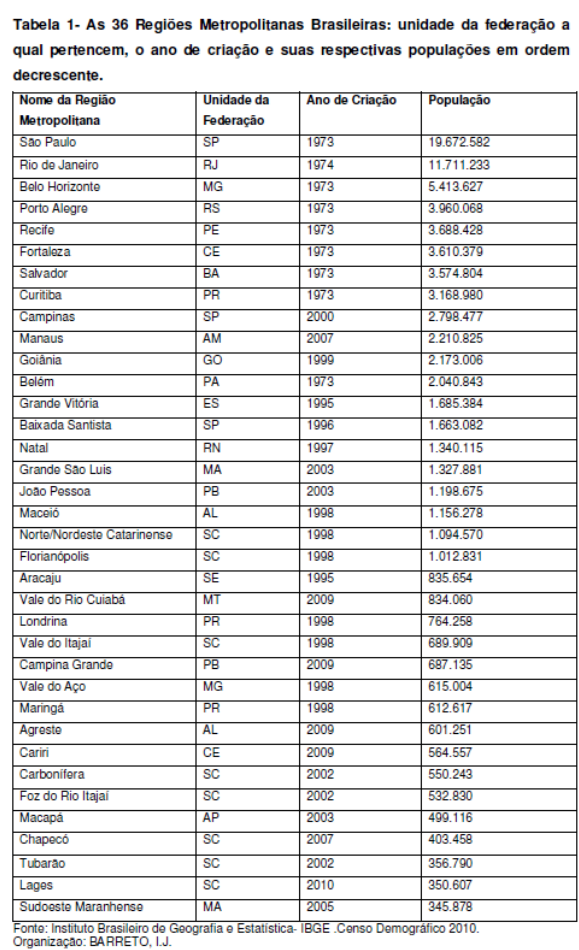

FONTE : IBGE - CENSO DEMOgRÁfico 2010

ORgANIZAÇÃO : ILSON J. BARRETO

9 A disparidade quantitativa entre as regiões metropolitanas brasileiras também é evidenciada quando lançamos um olhar nas unidades da federação e verificamos o número de regiões metropolitanas ali existentes. Em alguns estados o rigor e a coerência no trato dos critérios que devem permear a criação de uma região metropolitana ficam mais evidenciados que outros. É o caso do Estado do Rio Grande do Sul que possui apenas uma região metropolitana: a de Porto Alegre, criada em 1973, a quarta mais populosa do país e com população próxima a quatro milhões de habitantes. Para outras três concentrações urbanas daquele estado foram institucionalizadas três aglomerações urbanas: a Aglomeração Urbana do Nordeste, a Aglomeração Urbana do Sul e Aglomeração Urbana do Litoral Norte. Na contramão do Rio Grande do Sul, está o vizinho estado de Santa Catarina. Existem ali atualmente oito regiões metropolitanas, todas institucionalizadas no período posterior a Constituição de 1988.

10 Decorrente da Constituição Federal de 1988, Santa Catarina foi um dos estados pioneiros na regulamentação da questão dos novos "espaços metropolitanos" onde, pela Lei 
Complementar à Constituição Catarinense nº 104/1994 e, posteriormente, pela lei 162/97, são instituídas oficialmente as primeiras regiões metropolitanas: Florianópolis, Vale do Itajaí e a do Norte/Nordeste Catarinense (MACHADO, 2008, p. 237).

11 O caso de Santa Catarina merece atenção neste momento, justamente pelo fato de ficar bastante evidente naquele estado - embora também aconteça em outras unidades da federação - uma visível ausência de critérios na institucionalização de novas regiões metropolitanas. Para começar, as referidas unidades político-administrativas possuem, em sua grande maioria, população inferior a um milhão de habitantes - incluindo a capital, Florianópolis - o que nos parece patamar mínimo populacional para se justificar uma discussão inicial sobre a criação de uma nova região metropolitana. Outro fato no mínimo curioso sobre as regiões metropolitanas catarinenses - e porque não dizer incoerente - que sinaliza mais uma vez para a falta de critérios dos políticos que legislam, e por conseqüência, responsáveis pela criação de novas regiões metropolitanas - é o fato de que por força da Lei Complementar 381/2007, todas as regiões metropolitanas daquele estado, criadas até então, terem sido extintas. Três anos depois, com a Lei Complementar 495/2010, as referidas regiões metropolitanas são recriadas. Isso só reforça a crítica sobre a precocidade com que as regiões metropolitanas são concebidas e a inconseqüência dos que as concebem. Sobre isso, Machado se faz bastante oportuno quando diz que:

"Essa trajetória de metropolização em territórios catarinenses tem suscitado críticas, muitas das quais relacionadas quase sempre aos critérios adotados e o que deles efetivamente explicam e justificam as ações políticas, sem atender a quaisquer critérios urbanísticos e econômicos que justifiquem tais deliberações" (MACHADO, 2008, p. 238).

O poder legislativo estadual, tanto no caso catarinense quanto em vários outros estados brasileiros, tem se mostrado, a nosso ver, na grande maioria das vezes, incapaz de fazer a contento proposições relativas à criação de novas regiões metropolitanas, fato evidenciado quando observamos a quantidade dessas unidades regionais institucionalizadas a partir da Constituição de 1988. Além disso, a inexistência de audiências com representantes políticos dos municípios envolvidos, assim como, da sociedade civil parece estar sendo a regra, uma vez que muitas dessas representações regionais são sequer consultadas a respeito. Isso só reforça o caráter eminentemente político que acompanha tais proposições.

Essa sucessão demonstra o profundo desconhecimento quanto ao fato urbanometropolitano por parte do legislativo e da própria sociedade, permitindo que, com a agilização do processo, se imponham processos meramente formais. Vislumbram também, resquícios da crença de que possam ser retomadas linhas de financiamentos voltadas a unidades regionais metropolitanas, presentes no início dos anos de 1970. Porém, o que prevalece é o desejo do status: mais que criar regiões, se instituem metrópoles, associadas ao peso simbólico que as relaciona ao progresso e a modernidade (FIRKOWSKI \& MOURA, 2001, p.32).

14 Mas, na prática, de que argumentações se valem os políticos para justificar a criação de uma nova região metropolitana? Nas entrevistas que temos realizado junto a vários deputados estaduais e na observância dos discursos envolvendo os defensores da criação de tais unidades político-regionais, a integração e o desenvolvimento regional tem sido o fio condutor na fala dos mesmos. O discurso político, traz a promessa de uma aproximação entre os municípios que comporiam a virtual região metropolitana, na busca de resolução de problemas comuns entre eles e se apresenta como solução para todos os 
males de municípios tão próximos geograficamente, e, por muitas vezes, distantes, em especial, no que tange às suas realidades econômicas: distantes na prática, tão próximos no discurso.

Outro elemento ou argumento que se apresenta com bastante destaque é o de que com a composição política que passa a existir com a institucionalização da região metropolitana, os integrantes desta composição, agora têm "voz" no requerimento de financiamentos e verbas junto aos poderes político estadual e federal e, até mesmo na negociação de empréstimos junto aos organismos financeiros internacionais.

Ainda no tocante ao período gestacional de uma região metropolitana, merece destaque o trabalho, de cunho ideológico, feito junto aos cidadãos dos municípios que comporiam a mesma. Estes cidadãos são sugestionados a incorporar a condição de "cidadão metropolitano", onde as barreiras político-administrativas entre os municípios já não teriam tanto significado assim; começa a se forjar o "cidadão metropolitano".

\section{Governo metropolitano: a pouca autonomia dos espaços institucionalizados}

Um fator extremamente relevante e que acaba sendo sucumbido pela "euforia" política e estrategicamente criada diante da sugestão de surgimento de uma nova região metropolitana, é o que diz respeito a governo metropolitano. 0 que se tem visto, via de regra, no quadro metropolitano nacional, é ainda, uma limitação na tomada de decisões no interior das mesmas, evidenciando a pouca autonomia que têm estas composições heterogêneas, porém, que almejam soluções para problemas que são comuns a todas.

Embora devamos considerar que a gestão tenha alcançado alguns avanços, numa ou outra região metropolitana, de maneira geral, a ingerência do poder público estadual e federal é latente e pior, acontece com poucos ganhos para as mesmas, já que tais ações pouco correspondem aos reais anseios dessas unidades regionais; justamente pelo fato de que tais ações vêm, em boa parte das vezes, de fora para dentro e com pouca ou irrelevante participação dos agentes que efetivamente as integram. Vemos aí resquícios do "entulho autoritário" (SANTOS, 1993, p.32) no qual o Brasil estava inserido em período relativamente recente de sua história.

Longe de sugestões simples para o que é naturalmente complexo, não vislumbramos outro caminho para gestão metropolitana que não seja aquele onde haja compartilhamento dos temas que são comuns aos que são diretamente envolvidos: os municípios componentes de tais unidades político-administrativas, a sociedade nas suas mais diversas formas de representatividade e o Estado. Para Firkowiski e Moura "Apenas a conquista de um poder regional, que legitimamente decorra da articulação das forças que produzem o espaço, é que dará corpo a uma unidade de gestão" (FIRKOWSKI \& MOURA, 2001, p.35)

No bojo da metropolização do espaço, que por ser processo, não respeita os limites político-administrativos previamente definidos, a gestão metropolitana tem a sua frente mais um desafio: espaços com visíveis características de metropolização estão fora da área institucionalizada; em contrapartida, no interior da região metropolitana é possível verificar áreas em total descompasso com a dinâmica metropolitana. 


\section{0 projeto de lei que cria a região metropolitana de Sorocaba}

Em 2005, através do Projeto de Lei Complementar nº 33, o Deputado Estadual Hamilton Pereira sugere à Assembleia Legislativa Estadual de São Paulo, a criação da Região Metropolitana de Sorocaba. Tal Projeto de Lei ${ }^{1}$ ainda tramita na referida Casa e Leis mas, desde então, vem provocando, principalmente em nível local e regional, uma série de debates e discussões a respeito da iniciativa do referido deputado, em especial, no que tange às viabilidades de um Projeto de tanta magnitude para a cidade de Sorocaba e todos os municípios que comporiam esta Região Metropolitana (Figura 1). Em seguida, na tabela 2, podemos observar os municípios elencados no Projeto de Lei que cria a Região Metropolitana de Sorocaba, suas populações, áreas e densidades demográficas:

Figura 1

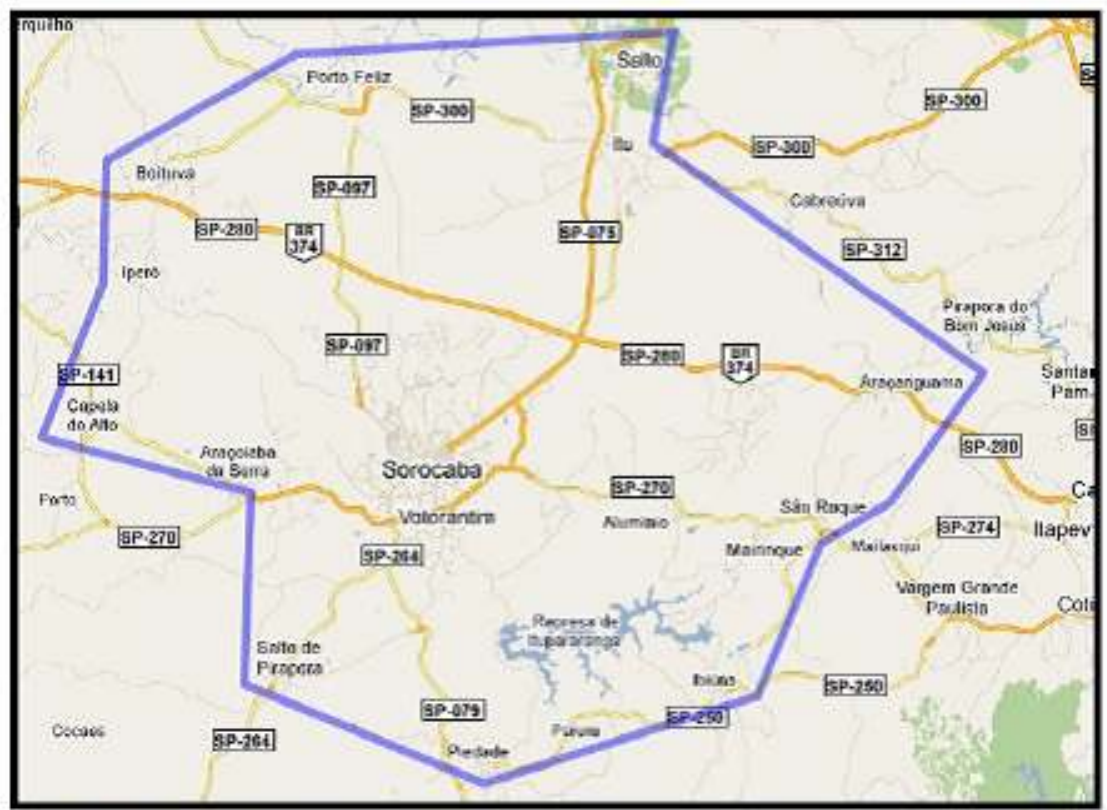

Figura 1 - Delimitaçao da ârea que abrange os 16 municipios que comporiam a virtual Regiao Metropolitana de Sorocaba.

Fonte: Google Maps

Organizaçao: BARRETO, L J. 
Tabela 2

\begin{tabular}{|c|c|c|c|}
\hline MUNICIPIO & POPULAÇAO & AREA $\left(\mathrm{km}^{2}\right)$ & $\begin{array}{l}\text { DENSIDADE } \\
\text { DEMOGRAFICA }\end{array}$ \\
\hline BOITUVA & 48314 & 249 & 194,07 \\
\hline CAPELAA DO ALTO & 17532 & 169,9 & 103,20 \\
\hline ALUMinIO & 16839 & $\beta 3,8$ & 200,92 \\
\hline Apa ÇAAIGUAMA & 17080 & 146,3 & 116,72 \\
\hline APA ÇOAABA DA SERPA & 27299 & 255,4 & 106,87 \\
\hline IBIÚNA & 71217 & 1057,7 & 67,34 \\
\hline IPEÁ́ & 28300 & 170 & 166,42 \\
\hline ITU & 154147 & 640,8 & 240,57 \\
\hline MAIRINOUE & 43223 & 209,6 & 206,18 \\
\hline PIEDADE & 52143 & 746,9 & 69,82 \\
\hline PORTO FELIZ & 48893 & 557,1 & 37,76 \\
\hline SALTO DE PIFAPORA & 40132 & 280,5 & 143,07 \\
\hline SALTO & 105516 & 133,2 & 792,17 \\
\hline SAO ROOUE & 78821 & 306,3 & 257,30 \\
\hline SOPOCABA & 596625 & 449 & 1306,55 \\
\hline VOTOPANTIM & 108809 & 183,7 & 592,47 \\
\hline TOTAL & 1.444 .890 & 5662 & $255^{\circ}$ \\
\hline \multicolumn{4}{|c|}{$\begin{array}{l}\text { Fonte: IBGE - dados sobre a populaçaa-Censo } 2010 \\
\text { Organizaçao: BARRETO. L. J. } \\
\text { - Densidade demográfica média }\end{array}$} \\
\hline
\end{tabular}

No Projeto de Lei supracitado, o deputado Hamilton Pereira justifica a sua proposição que cria a Região Metropolitana de Sorocaba: Tais números demonstram a elevada densidade demográfica dessa região. Ressalte-se que a maior distância entre as localidades elencadas no $\S 1^{\circ}$ do art. $1^{\circ}$ desta propositura, não ultrapassa 45 (quarenta e cinco) quilômetros do município sede da região - Sorocaba, evidenciando significativa conurbação. Afora isso, as funções urbanas e regionais desse agrupamento de municípios contam com um elevado grau de diversidade, especialização e integração socioeconômica, tendo em vista que a ligação entre esses municípios, à Capital e às outras regiões do Estado é realizada por importantes rodovias, tais como a Rodovia Presidente Castello Branco (SP 280), a Rodovia Raposo Tavares (SP 270), a Rodovia Marechal Rondon (SP 300) e a Rodovia Senador José Ermírio de Moraes (Castelinho - SP 075) ( PEREIRA, 2005).

A institucionalização de novas regiões metropolitanas no país, de maneira geral, vem correspondendo muito mais aos anseios políticos do que propriamente os geográficos $\mathrm{e}$ urbanísticos (HENRIQUE, 2007, p.50) demonstrando, como já dito, o pouco conhecimento dos que fazem tais proposições. Embora de maneira incipiente, aspectos da metropolização do espaço já são perceptíveis em Sorocaba e alguns municípios de sua hinterlândia, desde o final do século passado, merecendo destaque o eixo que vai desta última até Salto, passando pela cidade de Itu. Tal constatação, porém, nos coloca à mostra o fato de que a metropolização do espaço têm ultrapassado os limites políticoadministrativo da metrópole; neste caso, da maior região metropolitana do país, sabidamente, a Região Metropolitana de São Paulo.

Assim sendo, de forma resumida. Podemos dizer que o processo de metropolização do espaço não se restringe à região metropolitana. Em outros termos, o processo de 
metropolização do espaço não diz respeito apenas à Região Metropolitana; ou seja, não é exclusivo da metrópole e nem se confina mais nas fronteiras da região metropolitana. (LENCIONI, 2003, p. 36).

Em entrevista com o autor do Projeto de Lei que sugere a criação da Região Metropolitana de Sorocaba, o deputado estadual Hamilton Pereira, percebemos no mesmo, um grande entusiasmo, em especial, em função do fato de o referido Projeto já ter tramitado e sido aprovado por várias comissões no interior da Assembleia Legislativa do Estado de São Paulo; hoje, sabemos que tal Projeto de Lei já foi aprovado inclusive pela Comissão de Assuntos Metropolitanos, portanto, em estágio bastante avançado de tramitação no seio da referida Casa de Leis. Em contrapartida, o governador do Estado de São Paulo, Geraldo Alckmin anunciou no último mês de abril, em visita a cidade de Sorocaba, que, junto com sua assessoria, estava em fase final de elaboração de um Projeto de Lei que cria o Aglomerado Urbano de Sorocaba. Independentemente da forma de organização políticoregional proposta, vemos que ainda falta maturidade e vontade política no sentido de se promover no âmbito da região a ser institucionalizada uma intensa discussão - como já dito - com os vários segmentos da sociedade, no sentido de se avaliar os verdadeiros ganhos com a referida institucionalização. Além disso, antes de se promover um "explosão" quantitativa na criação de tais unidades político-regionais, é preciso repensar a gestão metropolitana, que ainda se apresenta de modo bastante centralizado, portanto, com pouca autonomia política e financeira a tais unidades.

É sob esse enfoque que também passa a ser cogitada a definição de um projeto de gestão metropolitana, que inclui a de um parlamento metropolitano, investido de múltiplas atribuições - entre outras, a de preencher lacunas deixadas pelos órgãos metropolitanos do período autoritário; ou a de implantar formas compartilhadas de poder, não limitadas ao setor público, evitando assim problemas de centralização e de hegemonia de um município; ou ainda, a de pleitear e garantir a autonomia política e financeira dos municípios da região metropolitana, levando em conta o reduzido afluxo de recursos e a diminuição relativa da parcela de receitas próprias na receita total.

Por fim, nos moldes em que se apresentam hoje a grande maioria das regiões metropolitanas brasileiras, em especial, do ponto de vista da pouca eficiência e autonomia de suas gestões, nos parece pertinente questionar a legitimidade de tais proposições. Assim sendo, uma nova região metropolitana: para que e para quem?

\section{Considerações finais}

Ao concluir nossas entrevistas com os prefeitos das cidades que comporiam a virtual Região Metropolitana de Sorocaba, percebemos junto a eles um significativo entusiasmo em torno da criação de tal unidade político-administrativa. Porém, aliado ao entusiasmo dos prefeitos, uma constatação bem clara é a de que os mesmos ainda possuem poucas informações sobre o que é na prática uma região metropolitana e quais os reais ganhos dos municípios que representam com a institucionalização de tal unidade políticoadministrativa. Uma queixa bastante ouvida entre os prefeitos é a de que sentem falta de audiências que tenham como objetivo esclarecer suas dúvidas a respeito do tema.

Em nossos trabalhos voltados à cidade e ao urbano, constatamos a importância da força política como poder decisório e incontestável na configuração e reconfiguração dos espaços regionais. Porém, temos como certo que, embora as ações políticas se apresentem 
muitas vezes como reveladora de verdades absolutas a ponto de nos induzir às respostas evidentes, de maneira nenhuma pode fugir do espírito crítico que deve alimentar aquele que se debruça sobre determinada pesquisa. Assim sendo, procuramos ter como eixomestre deste nosso trabalho, dois questionamentos centrais: a dinâmica regional justifica a criação de uma região metropolitana tendo como cidade pólo Sorocaba? Os sinais de metropolização vistos em Sorocaba e sua hinterlândia não seriam apenas evidência da expansão da chamada macrometrópole? Responder esses questionamentos a contento não é tarefa fácil, afinal de contas, não podemos nos esquecer de que nosso alvo de estudo está inserido na região mais dinâmica e complexa do país: a Região Metropolitana de São Paulo e todo o seu entorno.

Por fim, uma coisa já nos parece evidente no que se refere aos processos de criação das regiões metropolitanas. Em tais processos, tem havido, por muitas vezes, uma quase ausência de critérios, e um bom exemplo disso, é o fato de que muitas dessas unidades político-administrativas possuem como pólo central, cidades com bem menos de 500 mil habitantes, São os casos da cidade paranaense de Maringá, e da catarinense, Lages.

\section{BIBLIOGRAFIA}

IBGE (Instituto Brasileiro de Geografia e Estatística). Censo Demográfico 2010. Disponível em: http:// www.ibge.org.br. Acesso em 30/05/2011.

DAVIDOVICH, Fany. Metrópole e Contemporaneidade, Algumas Pontuações. In: CARLOS, Ana Fani Alessandri e LEMOS, Amália Inês Geraiges. (Orgs.). Dilemas Urbanos: Novas Abordagens sobre a Cidade . São Paulo: Contexto, 2003.

Metrópoles: entre a coesão e a fragmentação, a cooperação e o conflito. São Paulo: Editora Fundação Perseu Abramo; Rio de Janeiro: FASE, 2004.

FIRKOWSKI, Olga, MOURA, Rosa. Regiões Metropolitanas e Metrópoles. Reflexões Acerca das Espacialidades e institucionalidades no Sul do Brasil. RA'EGA (UFPR), p. 5, 2001.

HENRIQUE, Wendell. A Recente Metropolização em Santa Catarina: processo geográficoterritorial ou apenas um limite político-administrativo? Revista Geotextos. [on line]. Vol. 3, n. 1 e 2, 2007. Disponível em: http//www.portalseer.ufba.br.

LENCIONI, Sandra. Uma Nova Determinação do Urbano: o desenvolvimento do processo de metropolização do espaço. In: CARLOS, Ana Fani Alessandri e LEMOS, Amália Inês Geraiges. (Orgs.). Dilemas Urbanos: Novas Abordagens sobre a Cidade. São Paulo: Contexto, 2003.

MACHADO, Ewerton Vieira. (Re) arranjos Sócio-Espaciais na Produção da "Região Metropolitana" de Florianópolis: trajetórias e tendências. In: SOUZA, Maria Adélia de (org.). A Metrópole e o Futuro. Campinas: Edições Territorial, 2008.

SÃo PAULO, Assembleia Legislativa do Estado de. Projeto de Lei $n^{\circ} 33$ de 2005. Disponível em: $<$ http//www.al.sp.gov.br>. Acesso em 25/08/11. 
SANTOS, Milton. Involução Metropolitana e Economia Segmentada. O caso de São Paulo. In: RIBEIRO, Ana C.T. et al (org.). Seminário Metropolização e Rede Urbana, Perspectivas dos anos 90. Rio de Janeiro: IPPUR/UFRJ, 1993.

\section{NOTAS}

1. Aprovado em todas as comissões pelas quais tramitou na Assembléia Legislativa do Estado de São Paulo: Comissão de Constituição e Justiça; Comissão de Assuntos Metropolitanos; Comissão de Assuntos Municipais; Comissão de Finanças e Orçamento.

\section{RESUMOS}

No ano de 1973, sob a égide do governo militar, surgiram as nove primeiras regiões metropolitanas brasileiras no contexto da estratégia desenvolvimentista de tal governo. A partir da Constituição de 1988, a incumbência na criação de tais unidades político-regionais passa a ser dos legislativos estaduais. 0 que se vê então são dezenas de Projetos de Lei criando novas regiões metropolitanas no país. Até que ponto existe coerência em tais proposições? É o que pretendemos discutir com este artigo tendo como pano de fundo a proposta da criação da Região Metropolitana de Sorocaba.

In 1973, under the aegis of the military government emerged the first nine metropolitan regions in the context of the development strategy of this government. From the 1988 Constitution, the task in the creation of such regional-political units becomes the state legislatures. What we see then are dozens of Bills creating new metropolitan areas in the country. To what extent is there consistency in such propositions? That's what we intend to discuss with this article having as background the proposal to create the Metropolitan Region of Sorocaba.

En 1973, sous l'égide du gouvernement militaire et dans le contexte du développementisme, on a vu l'émergence des premières neuf régions métropolitaines brésiliennes. Depuis la Constitution de 1988, quand les états sont devenus les responsables pour la création de ces régions, on a vu la multiplication de régions métropolitaines. A partir de la proposition de l'apparition de la Région Métropolitaine de Sorocaba (São Paulo), on va discuter la cohérence de ces propositions.

\section{ÍNDICE}

Palavras-chave: região metropolitana, metrópole, metropolização, Sorocaba, Brasil

Mots-clés: région métropolitaine, métropole, métropolisation, Sorocaba, Brésil

Keywords: metropolitan region, metropolis, metropolization, Sorocaba, Brazil 


\section{AUTOR}

\section{ILSON JULIANO BARRETO}

Doutorado em Geografia pela Universidade Estadual Paulista Júlio de Mesquita Filho, UNESP - Rio Claro. Bolsista da Fundação de Amparo à Pesquisa do Estado de São Paulo, FAPESP, Brasil. E-mail: ilsonjuliano@hotmail.com 